Int. J. Dev. Biol. 56: 193-196

doi: $10.1387 / \mathrm{ijdb} .113486 \mathrm{op}$

\title{
Planarians in pharmacology: parthenolide is a specific behavioral antagonist of cocaine in the planarian Girardia tigrina
}

\author{
ONÉ R. PAGÁN ${ }^{*}, 1$, DEBRA BAKER ${ }^{1}$, SEAN DEATS ${ }^{2}$, ERICA MONTGOMERY ${ }^{1}$, \\ MATTHEW TENAGLIA ${ }^{1}$, CLINITA RANDOLPH ${ }^{1}$, DHARINI KOTTURU ${ }^{1}$, CHRISTOPHER TALLARIDA ${ }^{3}$, \\ DANIEL BACH ${ }^{1}$, GALIA WILK ${ }^{1}$, SCOTT RAWLS ${ }^{4}$ and ROBERT B. RAFFA ${ }^{3}$ \\ ${ }^{1}$ Department of Biology, West Chester University, West Chester, ${ }^{2}$ Department of Psychology, West Chester \\ University, West Chester, ${ }^{3}$ Department of Pharmaceutical Sciences, Temple University School of Pharmacy, \\ Philadelphia and ${ }^{4}$ Department of Pharmacology, Temple University School of Medicine, Philadelphia, PA, USA
}

\begin{abstract}
Planarians are traditional animal models in developmental and regeneration biology. Recently, these organisms are arising as vertebrate-relevant animal models in neuropharmacology. Using an adaptation of published behavioral protocols, we have described the alleviation of cocaine-induced planarian seizure-like movements (pSLM) by a naturally-occurring sesquiterpene lactone, parthenolide. Interestingly, parthenolide does not prevent the expression of pSLM induced by amphetamines; in vertebrates, amphetamines interact with the same protein target as cocaine. Parthenolide is also unable to prevent pSLM elicited by the cholinergic compounds nicotine and cytisine or by the glutamatergic agents L- or D- glutamic acid or NMDA. Thus, we conclude that parthenolide is a specific anti-cocaine agent in this experimental organism.
\end{abstract}

KEY WORDS: planaria, parthenolide, cocaine, amphetamine, seizures, behavior

\section{Introduction}

Planarians are one of the best-characterized animal models in developmental biology and regeneration research (Newmark and Sánchez Alvarado, 2002) and are currently being rediscovered as a very useful animal model in neuropharmacology (Buttarelli et al., 2008; Raffa and Rawls, 2008). Planarians are the first extant example of organisms displaying cephalization, including a primitive brain, sometimes referred to as cerebral ganglia, with many features in common with vertebrate nervous systems, such as multipolar neurons and dendritic spines (Sarnat and Netsky, 1985). Additionally, nearly every neurotransmitter found in mammals is present in planarians (Buttarelli et al., 2008; Ribeiro et al., 2005). One of the most interesting properties of this class of organisms is their remarkable capacity for regeneration, including the complete regeneration of their cerebral ganglia upon decapitation (Cebrià, 2007; Cebrià et al., 2002; Gentile et al., 2011). Working with this organism has several practical advantages. They are commercially available at very low cost and are very easily kept in the laboratory. No special equipment such as incubators, etc., is necessary. Additionally, the genome of a planarian species (Schmidtea mediterranea) has been sequenced (Robb et al., 2008), which will undoubtedly help to understand these organisms at the molecular level.

Two specific planarian behavioral endpoints have proven useful in pharmacological experiments: the observation of changes in motility (Raffa et al., 2001) and the induction of planaria seizure-like movements (pSLM; Rawls et al., 2011; Fig. 1A). Both responses are easily quantified and have been used to study the effect of a wide variety of psychoactive agents and abused drugs (Raffa and Rawls, 2008; Rawls, 2011).

Parthenolide (Fig. 1B) is the active component of the feverfew plant ( $T$. parthenium), used to treat migraines. This compound has several known biochemical effects, including the inhibition of serotonin type II receptors (Weber et al., 1997) and the enhancement of NF-kB transcription factor function (Kang et al., 2002). Also, parthenolide displays anti-inflammatory effects and inhibits Ikappa-B kinases (Kwok et al., 2001).

Parthenolide and related compounds have been shown (1) to prevent the expression of cocaine-induced behaviors in planarians, such as motility decrease and seizure-like hyperkinesias (Pagán

Abbreviations used in this paper: DAT, dopamine transporter; MAT, monoamine transporter; NET, norepinephrine transporter; NMDA, N-Methyl-D-Aspartate;pSLM, planarian seizure-like movements; SERT, serotonin transporter.

\footnotetext{
*Address correspondence to: Oné R. Pagán. Department of Biology, West Chester University, West Chester, PA 19383, USA. Tel: +1 610-436-2165.

Fax: +1 610-436-2183. e-mail: opagan@wcupa.edu
}

Final, author-corrected PDF published online: 16 March 2012

ISSN: Online 1696-3547, Print 0214-6282

(C) 2012 UBC Press

Printed in Spain 
et al., 2008) and (2) to prevent the expression of withdrawal-like behaviors induced by cocaine (Rowlands and Pagán, 2008). The lactone moiety of the parthenolide molecule is essential for its cocaine-antagonist properties (Pagán et al., 2008). Further work established that the lactone moiety with a 4-methyl tail is sufficient to prevent the motility decrease induced by cocaine (Baker et al., 2011). Significantly, similar results have been observed in vertebrates. Parthenolide alleviates the cocaine-induced effects on spontaneous firing of dopaminergic neurons in the ventral tegmental area of rats (Schwarz et al., 2011).

Here we report that parthenolide prevents the pSLMs induced by cocaine but not the hyperkinesia induced by amphetamines, the cholinergic ligands nicotine and cytisine, or the glutamatergic ligands L- of D-glutamic acid and NMDA. These results suggest that parthenolide is a specific behavioral antagonist for cocaine in our experimental conditions.

\section{Results}

Fig. $1 \mathrm{C}$ shows that parthenolide up to a concentration of $50 \mu \mathrm{M}$ does not induce significant pSLMs. This is consistent with previous reports, which show that at this concentration, parthenolide does not seem to produce any behavioral effects on the planarians (Pagán et al., 2008; Rowlands and Pagán, 2008). Based on this, we used parthenolide at a concentration of $50 \mu \mathrm{M}$ in all subsequent experiments. Fig. 1D shows that that $50 \mu \mathrm{M}$ parthenolide prevents the
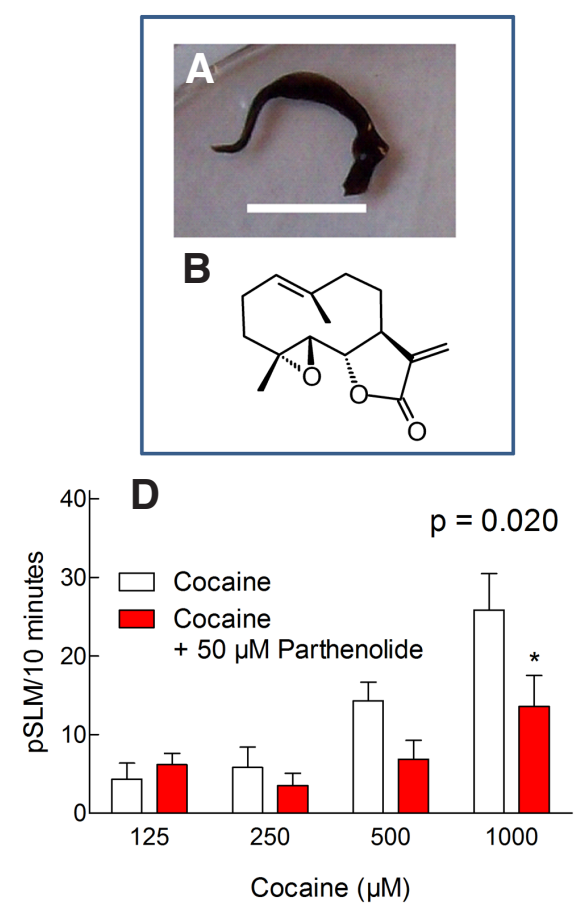
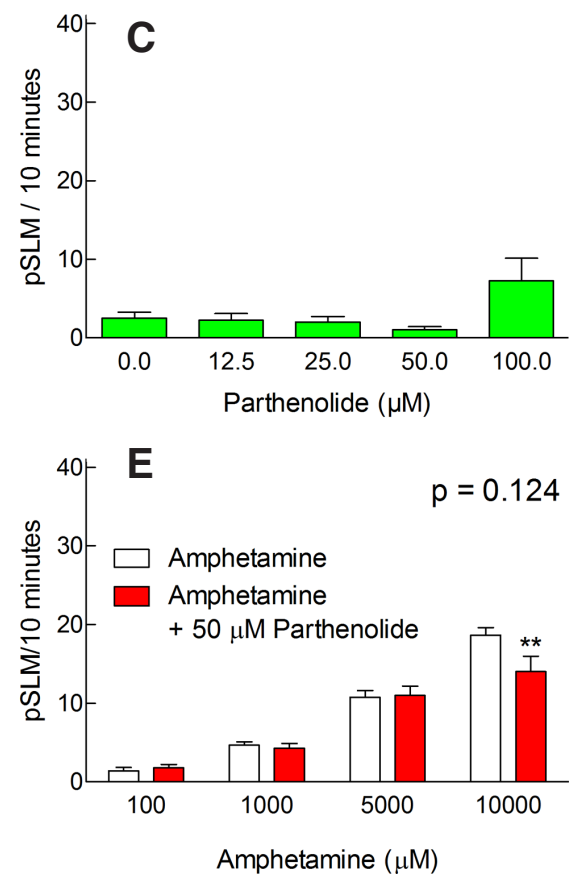

Fig. 1. Effect of parthenolide against cocaine and amphetamine. (A) Representative planarian seizure-like movement. The white bar is $1 \mathrm{~cm}$ long. (B) Parthenolide structure. (C) Parthenolide does not induce significant pSLMs. Each bar is the average of 4 worms. (D) Cocaine-induced pSLMs in the presence and in the absence of $50 \mu \mathrm{M}$ parthenolide. (E) Amphetamine-induced pSLMs in the presence and in the absence of $50 \mu \mathrm{M}$ parthenolide. Each bar is the average of 4-8 worms. The error bars represent the standard error of the mean. The number at the upper right corner of $(D, E)$ represent the $p$-values generated by two-way ANOVA. The asterisks over some of the bars indicate significant difference between the column pairs " $" * 0.05$; "**" $<0.01)$ via a Bonferroni post-test. induction of cocaine-induced pSLM, as described before (Pagán al., 2008). Interestingly, parthenolide did not alleviate the be(Fig. 1E). However, not indicate a statistical difference between the worms exposed metamine and the worms exposed to amphetamine/parthein the whole curves, parthenolide significantly reduces the cholinergic agents nicotine and cytisine (Fig. acid or NMDA (Fig. 2 C,D,E).

\section{Discussion}

The negative results of parthenolide against all tested compounds except cocaine indicate a very important property of parthenolide, specificity. In clinical pharmacology, one of the main problems associated with medications are side effects, which are brought about by the interaction of a particular drug with multiple targets (Sheridan, 2003).

The accepted target for cocaine and amphetamines is the monoamine transporter (MAT) superfamily, which includes the dopamine transporter (DAT), the serotonin transporter (SERT) and the norepinephrine transporter (NET) (Torres et al., 2003). The main function of the MATs is to regulate neurotransmitter reuptake to the presynaptic terminal, hence regulating neurotransmission (Zahniser and Doolen, 2001). Neurotransmitter reuptake by specialized transporters was proposed as an inactivation mechanism as early as 50 years ago using radiolabeled noradrenaline (Hertting and Axelrod, 1961). The effect of cocaine in noradrenaline reuptake was also demonstrated using the same technique (Hertting et al., 1961). Since then, this inactivation mechanism has been demonstrated in many neurotransmitter systems (Torres et al., 2003). When abused drugs such as cocaine and amphetamine interact with the DAT, the dopamine concentration increases in the synaptic cleft; this increase causes a direct hyperactivation of postsynaptic dopamine receptors as well as extrasynaptic dopamine autoreceptors (Callier et al., 2003). In fact, one of the main roles of the DAT seems to be the regulation of dopamine spillover to these autoreceptors (Cragg and Rice, 2004). In humans, the main target for cocaine and amphetamine is the DAT (Uhl et al., 2002). Interestingly, DAT-knockout rodents are still sensitive to cocaine through increased participation of the NET and SERT in this process (Hall et al., 2004).

In light of this information, our results showing that parthenolide prevented the behavioral effects of cocaine but not amphetamine was unexpected, since cocaine and amphetamines both interact with neurotransmitter transporters, albeit through different mechanisms. Cocaine 

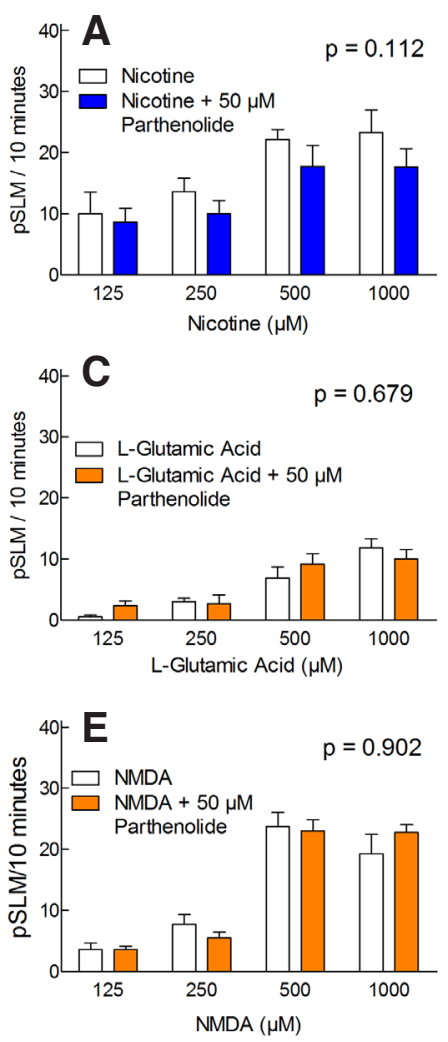
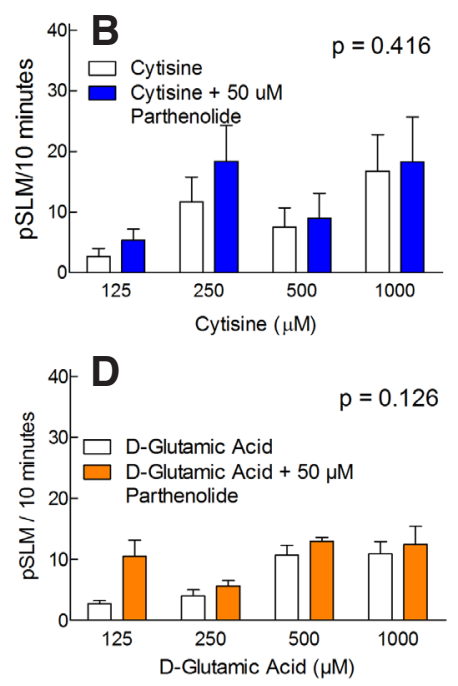

Fig. 2. Parthenolide does not display behavioral antagonism against cholinergic and glutamatergic compounds. Parthenolide does not prevent the expression of pSLMs induced by the cholinergic compounds nicotine (A) and cytisine (B) or by the glutamatergic compounds L-glutamic acid (C), D-glutamic acid(D) orNMDA

(E). The number at the upper right corner of each graph represent the p-values generated by two-way ANOVA. Each bar is the average of 5-10 worms. The error bars represent the standard error of the mean.

is a reuptake blocker, preventing the transport of the neurotransmitter back to the presynaptic site; amphetamine is considered a "releaser", which acts as a false substrate of the transporter (Riddle et al., 2005). In both cases, the net result is the abnormal increase of neurotransmitter molecules in the synaptic cleft, which accounts for the drug's psychoactive properties (Iversen, 2006; Sager and Torres, 2011).

Using vertebrate pharmacology as a point of reference, our results suggests that parthenolide prevents the pSLM induced by cocaine by inhibiting an interaction with dopaminergic systems. However, this is not consistent with the amphetamine results (Fig. 1E) or by the fact that no significant pSLMs are detected when exposing the worms to a dopamine concentration of $1 \mathrm{mM}$ (data not shown). Interestingly, preliminary results with another planarian species, Dugesia dorotocephala, seem to indicate that parthenolide alleviates amphetamine-induced pSLM (Rawls et al., unpublished data). A possible interpretation is that in planarians, any catecholamine responses are modulated by compounds such as norepinephrine, octopamine or tyramine, as opposed to dopamine. Another implication of our results is that the pSLM are induced by cocaine/amphetamines and by cholinergic/glutamatergic compounds by interacting with different protein targets. This is amenable to pharmacological dissection of these distinct mechanisms.

In future experiments, we will study the effect of parthenolide against cocaine and amphetamine-like compounds in planarian behavior using paradigms such as conditioned place preference (Rawls et al., 2011), cross-sensitization (Rawls et al., 2010) and withdrawal-like behavior (Sacavage et al., 2008).

In a broader context, this work highlights the usefulness of planarians as an important animal model in pharmacology. In addition to the multiple advantages of using planarians described above, this model has been demonstrated to be relevant to mammalian pharmacology (Schwarz, 2011). Furthermore, since they can be studied all the way from molecular biology to behavior, these organisms will likely be developed as important tools in drug discovery research.

\section{Materials and Methods}

Girardia tigrina were purchased from Ward's (Rochester, NY). The tested compounds were obtained from Sigma-Aldrich (St. Louis, $\mathrm{MO}$ ) or Tocris (Ellisville, MO). General laboratory materials were purchased from Fisher Scientific (Suwanee, GA). All graphs and statistical procedures were done using the Prism software package (GraphPad Inc., La Jolla, CA). The experiments were carried out at room temperature using artificial pond water (APW, $\mathrm{NaCl}, 6 \mathrm{mM}$; $\mathrm{NaHCO}_{3}, 0.1 \mathrm{mM} ; \mathrm{CaCl}_{2}, 0.6 \mathrm{mM}$ ). Dimethylsulfoxide (DMSO) at a concentration of $0.1 \%$ was present in all experimental solutions as a solubility-aiding agent for parthenolide. At this concentration, DMSO does not induce any observable behavioral or toxic effects in planarians (Pagán et al., 2006).

\section{Acknowledgments}

We are very grateful for the financial and institutional support from the Department of Biology, the College of Arts \& Sciences and the Office of Sponsored Research, West Chester University. We also gratefully acknowledge the funds provided by the National Institutes of Health (NIH); R03-DA026518(ORP) and R01-DA15378 (RBR). The NIH did not have any role in this report's study design, in the collection, analysis and interpretation of data, in the writing of the report or in any process related to the submission of this the paper for publication. None of the authors of this report have any kind of conflict of interest.

\section{References}

BAKER, D., DEATS, S., BOOR, P., PRUITT, J., PAGÁN, O.R. (2011) Minimal structural requirements of alkyl $\gamma$-lactones capable of antagonizing the cocaine-induced motility decrease in planarians. Pharmacol Biochem Behav. 100: 174-179.

BUtTARELLI, F.R., PELLICANO, C., PONTIERI, F.E. (2008) Neuropharmacology and behavior in planarians: translations to mammals. Comp Biochem Physiol C Toxicol Pharmacol. 147: 399-408.

CALLIER, S., SNAPYAN, M., LE CROM, S., PROU, D., VINCENT, J.D., VERNIER, P. (2003) Evolution and cell biology of dopamine receptors in vertebrates. Biol Cell. 95: 489-502.

CEBRIÀ, F. (2007) Regenerating the central nervous system: how easy for planarians! Dev Genes Evol. 217: 733-748.

CEBRIÀ, F., KUDOME, T., NAKAZAWA, M., MINETA, K., IKEO, K., GOJOBORI, T., AGATA, K. (2002) The expression of neural-specific genes reveals the structural and molecular complexity of the planarian central nervous system. Mechanisms of Development. 116: 199-204.

CRAGG, S.J., RICE, M.E. (2004) DAncing past the DAT at a DA synapse. Trends Neuroscience 27: 270-277.

GENTILE, L., CEBRIÀ, F., BARTSCHERER, K. (2011) The planarian flatworm: an in vivo model for stem cell biology and nervous system regeneration. Dis Model Mech. 4: 12-19.

HALL, F.S., SORA I, D.R., GONOVA, J., LI, X.F., GOEB, M., UHL, G.R. (2004). Molecular mechanisms underlying the rewarding effects of cocaine. Ann NY Acad Sci. 1025: 47-56.

HERTTING, G., AXELROD, J. (1961) Fate of tritiated noradrenaline at the sympathetic 
nerve-endings. Nature. 192: 172-173.

HERTTING, G., AXELROD, J., PATRICK, R.W. (1961) Actions of cocaine and tyramine on the uptake and release of $\mathrm{H} 3$-norepinephrine in the heart. Biochem Pharmacol. 8: 246-248.

IVERSEN, L. (2006) Neurotransmitter transporters and their impact on the development of psychopharmacology. Br J Pharmacol. 147 Suppl 1:S82-88.

KANG, S.N., KIM, S.H., CHUNG, S.W., LEE, M.H., KIM, H.J., KIM, T.S. (2002) Enhancement of 1 alpha,25-dihydroxyvitamin $\mathrm{D}$ (3)-induced differentiation of human leukaemia HL-60 cells into monocytes by parthenolide via inhibition of NF-kappa B activity. Br J Pharmacol. 135: 1235-1244.

KWOK, B.H., KOH, B., NDUBUISI, M.I., ELOFSSON, M., CREWS, C.M. (2001) The anti-inflammatory natural product parthenolide from the medicinal herb Feverfew directly binds to and inhibits lkappaB kinase. Chem Biol. 8: 759-766.

MINETA, K., NAKAZAWA, M., CEBRIA, F., IKEO, K., AGATA, K., GOJOBORI, T. (2003) Origin and evolutionary process of the CNS elucidated by comparative genomics analysis of planarian ESTs. Proc Natl Acad Sci USA. 100: 7666-7671.

NAKAZAWA, M., CEBRIÀ, F., MINETA, K., IKEO, K., AGATA, K., GOJOBORI, T. (2003) Search for the evolutionary origin of a brain: planarian brain characterized by microarray. Mol Biol Evol. 20: 784-791.

NEWMARK, P.A., SÁNCHEZ ALVARADO, A. (2002) Not your father's planarian: a classic model enters the era of functional genomics. Nat Rev Genet. 3: 210-219.

PAGÁN, O.R., ROWLANDS, A.L., FATTORE, A.L., COUDRON. T, URBAN, K.R., BIDJA, A.H., ETEROVIĆ, V.A. (2009) A cembranoid from tobacco prevents the expression of nicotine-induced withdrawal behavior in planarian worms. European Journal of Pharmacology. 615: 118-124.

PAGÁN, O.R., ROWLANDS, A.L., AZAM, M., URBAN, K.R., BIDJA, A.H., ROY, D.M., FEENEY, R.B., AFSHARI, L.K. (2008) Reversal of cocaine-induced planarian behavior by parthenolide and related sesquiterpene lactones. Pharmacol Biochem Behav. 89: 160-170.

PAGÁN, O.R., ROWLANDS, A.L., URBAN, K.R. (2006) Toxicity and behavioral effects of dimethylsulfoxide in planaria. Neurosci Lett. 407: 274-278.

RAFFA, R.B., HOLLAND, L.J., SCHULINGKAMP, R.J. (2001) Quantitative assessment of dopamine D2 antagonist activity using invertebrate (Planaria) locomotion as a functional endpoint. J Pharmacol Toxicol Methods. 45: 223-226.

RAFFA, R.B. AND RAWLS, S.M. (2008) Planaria: A Model for Drug Action and Abuse [Hardcover] Landes Bioscience, Inc.; 1st edition.
RAWLS, S.M., PATIL, T., TALLARIDA, C.S., BARON, S., KIM, M., SONG, K., WARD, S., RAFFA, R.B. (2011) Nicotine behavioral pharmacology: Clues from planarians. Drug Alcohol Depend. 118: 274-279.

RAWLS, S.M., PATIL, T., YUVASHEVA, E., RAFFA, R.B. (2010) First evidence that drugs of abuse produce behavioral sensitization and cross sensitization in planarians. Behav Pharmacol. 21: 301-313.

RIBEIRO P, EL-SHEHABI F, PATOCKA, N. (2005) Classical transmitters and their receptors in flatworms. Parasitology.131: S19-40.

RIDDLE, E.L., FLECKENSTEIN, A.E., HANSON, G.R. (2005) Role of monoamine transporters in mediating psychostimulant effects. AAPS J. 7: E847-851.

ROBB, S.M., ROSS, E., SÁNCHEZ ALVARADO, A. (2008) The Schmidtea mediterranea database as a molecular resource for studying platyhelminthes, stem cells and regeneration. Nucleic Acids Res. 36: D599-606.

ROWLANDS, A.L., PAGÁN, O.R. (2008) Parthenolide prevents the expression of cocaine-induced withdrawal behavior in planarians. Eur $J$ Pharmacol. 583: 170-172.

SACAVAGE, S., PATEL, H., ZIELINSKI, M., ACKER, J., PHILLIPS, A.G., RAFFA, R.B., RAWLS, S.M. (2008) Withdrawal-like behavior in planarians is dependent on drug exposure duration. Neurosci Lett. 439: 84-88.

SAGER, J.J., TORRES, G.E. (2011) Proteins interacting with monoamine transporters: current state and future challenges. Biochemistry. 50: 7295-7310.

SARNAT, H.B., AND NETSKY, M.G. (1985) The brain of the planarian as the ancestor of the human brain. Can J Neurol Sci. 12: 296-302.

SCHWARZ, D., BLOOM D., CASTRO, R., PAGÁN, O.R., JIMÉNEZ-RIVERA, C.A. (2011) Parthenolide blocks cocaine's effect on spontaneous firing activity of dopaminergic neurons in the ventral tegmental area. Curr Neuropharmacol. 9: 17-20.

SHERIDAN, R.P. (2003) finding multiactivity substructures by mining databases of drug-like compounds. J. Chem. Inf. Comput. Sci. 43: 1037-1050.

TORRES, G.E., GAINETDINOV, R.R., CARON, M.G. (2003) Plasma membrane monoamine transporters: structure, regulation and function. Nat Rev Neurosci. 4: 13-25.

UHL, G.R., HALL, F.S., SORA I. (2002) Cocaine, reward, movement and monoamine transporters. Mol Psychiatry. 7: 21-26.

ZAHNISER, N.R., DOOLEN, S. (2001) Chronic and acute regulation of $\mathrm{Na}+/ \mathrm{Cl}-$-dependent neurotransmitter transporters: drugs, substrates, presynaptic receptors, and signaling systems. Pharmacol Ther. 92: 21-55. 


\section{Further Related Reading, published previously in the Int. J. Dev. Biol.}

Planarian regeneration: achievements and future directions after 20 years of research Emili Saló, Josep F. Abril, Teresa Adell, Francesc Cebriá, Kay Eckelt, Enrique Fernández-Taboada, Mette Handberg-Thorsager, Marta Iglesias, M Dolores Molina and Gustavo Rodríguez-Esteban

Int. J. Dev. Biol. (2009) 53: 1317-1327

\section{Expression of a retinal homeobox $(\mathbf{R x})$ gene during planarian regeneration} Linda Mannini, Paolo Deri, Jacopo Picchi and Renata Batistoni Int. J. Dev. Biol. (2008) 52: 1113-1117

From Planarians to Mammals - the many faces of regeneration Jerzy Moraczewski, Karolina Archacka, Edyta Brzoska, Maria-Anna Ciemerych, Iwona Grabowska, Katarzyna Janczyk-Ilach, Wladyslawa Streminska and Malgorzata Zimowska Int. J. Dev. Biol. (2008) 52: 219-227

Expression of DjXnp, a novel member of the SNF2-like ATP-dependent chromatin remodelling genes, in intact and regenerating planarians

Leonardo Rossi, Paolo Deri, Ilaria Andreoli, Vittorio Gremigni, Alessandra Salvetti and Renata Batistoni

Int. J. Dev. Biol. (2003) 47: 293-298

Effects of activators and antagonists of the neuropeptides substance $P$ and substance $\mathrm{K}$ on cell proliferation in planarians

J Baguñà, E Saló and R Romero

Int. J. Dev. Biol. (1989) 33: 261-266

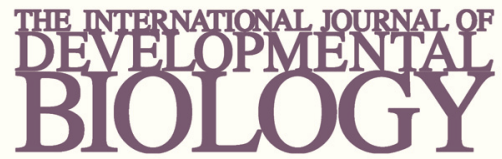

Volume 54 Nos. $6 / 7$
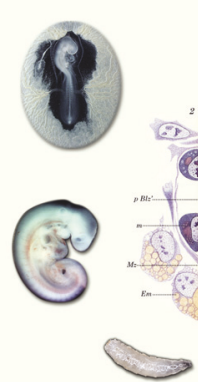

Developmental Hematopoiesi
Special Issue

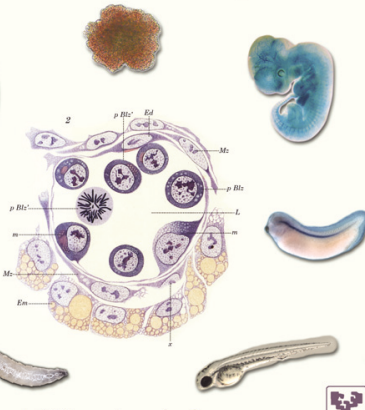

象?
5 yr ISI Impact Factor $(2010)=2.961$

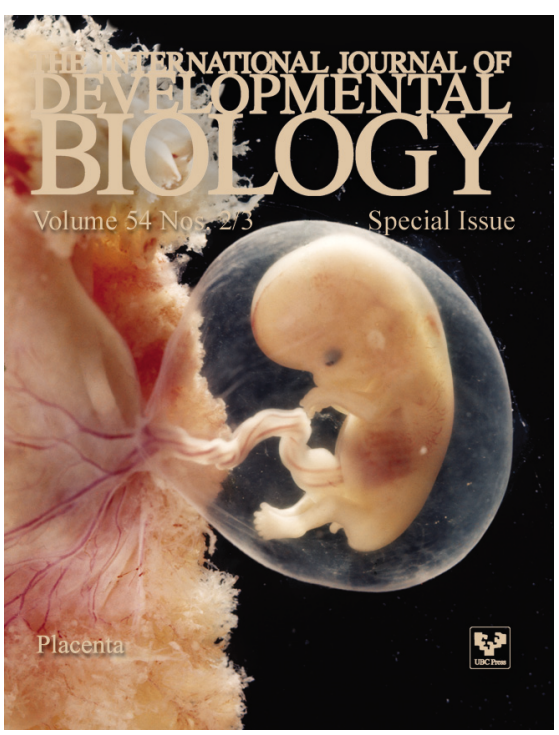

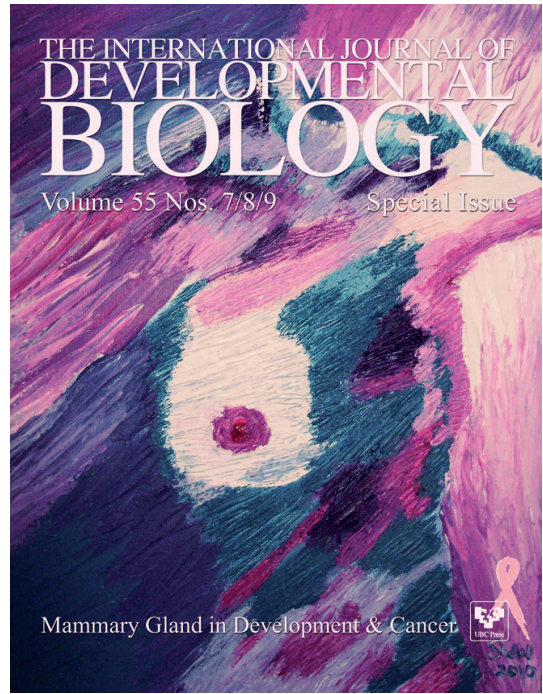

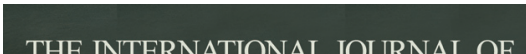

THE INTERNATIONAL JOURNAL OF DEVELOPMENTAL BOUOOY Volume 55 Nos. 4/5

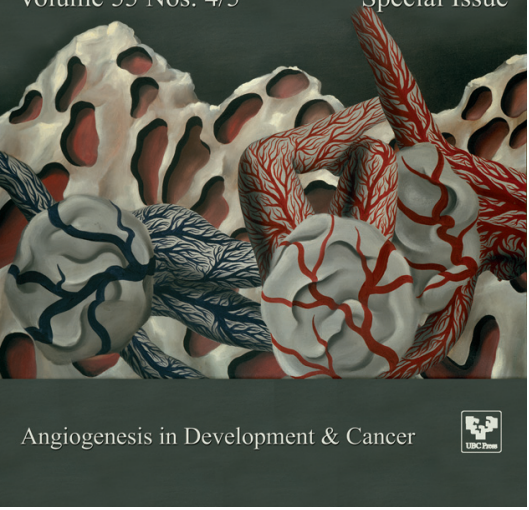

